\title{
Attention-Deficit/Hyperactivity Disorder in Children Undergoing Peritoneal Dialysis
}

\author{
Parsa Yousefichaijan ${ }^{1}$; Mojtaba Sharafkhah ${ }^{2,}$; Shams Vazirian ${ }^{3}$; Abolhasan Seyedzadeh ${ }^{3}$; \\ Mohammad Rafeie ${ }^{4}$; Bahman Salehi ${ }^{5}$; Mohammad Amiri ${ }^{6}$; Mohsen Ebrahimimonfared ${ }^{7}$ \\ ${ }^{1}$ Department of Pediatric Nephrology, Arak University of Medical Sciences, Arak, IR Iran \\ ${ }^{2}$ Students Research Committee, School of Medicine, Arak University of Medical Sciences, Arak, IR Iran \\ ${ }^{3}$ Department of Pediatric Nephrology, Kermanshah University of Medical Sciences, Kermanshah, IR Iran \\ ${ }_{5}^{4}$ Department of Biostatistics and Epidemiology, Arak University of Medical Sciences, Arak, IR Iran \\ 5 Department of Biostatistics and Epidemiology, Arak University of Medical S \\ ${ }_{6}$ Department of Psychiatry, Arak University of Medical Sciences, Arak, IR Iran
${ }_{\text {Department of Emergency Medicine, School of Medicine, Arak University of Medical Sciences, Arak, IR Iran }}$ \\ ${ }_{7}^{7}$ Department of Emergency Medicine, School of Medicine, Arak University of \\ ${ }^{*}$ Corresponding author: Mojtaba Sharafkhah, Students Research Committee, School of Medicine, Arak University of Medical Sciences, Zip Code: 3819693345, Arak, IR Iran. Tel: +98- \\ 9119180298, Fax:+98-8633133193, E-mail: sharafkhah@arakmu.ac.ir
}

Received: October 9, 2014; Revised: November 10, 2014; Accepted: November 15, 2014

\begin{abstract}
Background: Attention-deficit/hyperactivity disorder(ADHD) is the most common childhood psychiatric disorder. This disorder is more prevalent in some chronic disease.

Objectives: The aim of this study was to investigate ADHD in children with end-stage renal disease (ESRD) undergoing continuous ambulatory peritoneal dialysis (CAPD) and to compare the results with those of healthy children.

Patients and Methods: This case-control study was conducted for six months (December 22, 2013 to June 21, 2014) on five to 16-year-old children, visiting the Pediatric Dialysis Unit of Amirkabir Hospital, Arak, Iran, and Taleghani Hospital, Kermanshah, Iran. A total of 100 children with ESRD who had undergone CAPD for at least six months and 100 healthy children were included in this study as case and control groups, respectively. ADHD was diagnosed by Conner's Parent Rating Scale-48 (CPRS-48) and DSM-IV-TR criteria, and was confirmed through consultation by psychologist. Data were analyzed by Binomial test in SPSS 18.

Results: The ADHD inattentive type was observed in 16 cases ( $16 \%$ ) with CAPD and five controls $(5 \%)(\mathrm{P}=0.01)$. Moreover, ADHD hyperactiveimpulsive type was observed in 27 cases $(27 \%)$ with CAPD and seven controls $(9 \%)(\mathrm{P}=0.002)$. Despite these significant differences, no children were diagnosed with ADHD combined type among all subjects.

Conclusions: Inattentive type and hyperactive-impulsive type of ADHD are more prevalent in children with ESRD undergoing CAPD.

Therefore screening methods for ADHD is necessary in these patients.
\end{abstract}

Keywords: Attention Deficit Disorder with Hyperactivity; Child; Peritoneal Dialysis; Continuous Ambulatory

\section{Background}

Chronic kidney disease (CKD) is defined as a slow and steady damage of kidney function in an irreversible manner, which ends in end-stage renal disease (ESRD) (1,2). This chronic disorder is one of the problems of health of society with high prevalence in adults and children. It causes mortality, complications, and high costs due to poor prognosis and several diagnostic measures on patients (1). Peritoneal dialysis (PD), hemodialysis (HD), and finally renal transplantation are treatment strategy or renal replacement therapies (RRTs) in patients with ESRD. According to the North American Pediatric Renal Transplant Cooperative Study, one-fourth of the studied children underwent preemptive renal transplantation, half were on PD, and onefourth were on HD. Thus, long-term PD is the most commonly used RRT in children (2). Due to different reasons, RTT for CKD, especially for ESRD, can lead to psychiatric disorders in patients especially in children (3-6). According to previous findings, children with ESRD and PD are at higher risk of developing depression, delirium, and cognitive, anxiety, and adjustment disorders in comparison to children at the early stages of CKD, those who had undergone renal transplantation, and healthy children (3-6). Results of two separate studies on children with various stage of CKD indicated that the prevalence of adjustment and anxiety disorders is significantly higher in children with ESRD and PD than in healthy children and those who underwent renal transplantation $(4,7)$. Bakr et al. reported the prevalence of psychiatric disorders in children on PD and those at the early stages of CKD to be respectively $68.4 \%$ and $36.8 \%$ (3). Based on previous studies, children with CKD, who develop psychiatric and cognitive disorders, experience longer hospitalization and more complications and mortality compared to other patients at the same stage without these morbidities $(5,6)$.

Copyright ( ) 2015, Nephrology and Urology Research Center. This is an open-access article distributed under the terms of the Creative Commons Attribution-NonCommercial 4.0 International License (http://creativecommons.org/licenses/by-nc/4.0/) which permits copy and redistribute the material just in noncommercial usages, provided the original work is properly cited. 
Attention-deficit/hyperactivity disorder (ADHD) is the most common psychiatric disorder of childhood. As per DSM-IV criteria, ADHD includes inattentive type, hyperactive-impulsive type, and combined type (8). ADHD affects $5 \%$ to $10 \%$ of school-age children (9). The causes of ADHD in children are not clearly known; however, some evidence recognizes underlying genetic defect and central nervous system dysfunction as its main causes (10). ADHD can be significantly associated with a variety of childhood chronic disease (11-13), depression (13), behavioral, emotional, language, and hearing disorders $(14,15)$, and even illnesses such as epilepsy $(11,12)$ and abnormal findings in electroencephalogram of children (16). Similar to CKD, ADHD can be affected by such associated disorders regarding response to treatment and clinical course of disease (17-19). Concerning the association between ADHD and chronic diseases in childhood (17-19) and the importance of association between different degrees of CKD and psychiatric disorders $(5,6)$, the hypothesis regarding the association between ADHD and CKD in children undergoing PD was discussed.

\section{Objectives}

Regarding the limited number of investigations into the relationship between ADHD and different stages of CKD, this study aimed to investigating ADHD in children with ESRD who underwent continuous ambulatory PD (CAPD).

\section{Materials and Methods}

This case-control study was conducted for six months (December 22, 2013 to June 21, 2014) on 5 to 16 year-old children, visiting the Pediatric Dialysis Unit of Amirkabir Hospital, Arak, Iran, and Taleghani Hospital, Kermanshah, Iran. Totally, 100 children with ESRD who had undergone CAPD and 100 healthy children were included as case and control groups, respectively. Subjects were selected in a simple randomized way and based on inclusion and exclusion criteria.

ESRD or Stage 5 CKD was defined as the glomerular filtration rate (GFR) of $<15 \mathrm{~mL} / \mathrm{min} / 1.73 \mathrm{~m}^{2}$, which is an indicative of the start of dialysis $(20,21)$. The CAPD was defined as ambulatory PD for least six months (22). Clinical interviews with the children and their parents were performed to enroll patients according to the study the inclusion/exclusion criteria. We included children of both sexes in the age range of five to 16 years old, children with ESRD who had undergone CAPD, and written consent from patients' parents or guardians. We excluded patients with the following conditions: history of considerable psychiatric disorders; intellectual disabilities, or nervous system disorders; history of known ADHD before developing CKD and/or before undergoing PD; children with congenital and chromosomal abnormalities; history of sleep apnea or other sleeping disorders that can cause ADHD-like symptoms; and family history of major psychiatric disorders in first-degree relatives.
Intellectual disability was defined as the intelligence quotient (IQ) of $\leq 70$ (23). Healthy children were selected from children who had referred to two hospitals for common cold, abdominal pain, etc., as an outpatient. Matching method was used for selecting the healthy children and children were matched in two groups regarding age, sex, and socioeconomic status. After primary evaluation for eligibility criteria and obtaining informed consent from children's parents, demographic, clinical, and perinatal data (age, sex, birth weight, mother's age at birth, gestational age, maternal education, household incomes, marital status, siblings, type of delivery, and history of jaundice at birth), and duration of CAPD were recorded. ADHD was diagnosed by its DSM-IV criteria and Conner's Parent Rating Scale (CPRS). Based on A to $\mathrm{E}$ items of DSM-IV criteria, ADHD includes inattentive type, hyperactive-impulsive type, and combined type (8$10,14)$. ADHD inattentive type was defined as persistence of six (or more) symptoms of inattention (but fewer than six symptoms of hyperactivity-impulsivity) for at least six months. ADHD hyperactive-impulsive type was defined as persistence of six (or more) symptoms of hyperactivity-impulsivity (but fewer than six of inattention) for at least six months. ADHD combined type was defined as persistence of six or more symptoms of inattention and six or more symptoms of hyperactivity-impulsivity for at least six months.

The CPRS was standardized by Conners et al. in 1999. It has two 93-item and 48-item versions. The present research uses the 48 -item version (CPRS-48). This version evaluates five factors of conduct, psychosomatic-impulsivity, hyperactivity, anxiety, and learning problems and has four choices scored from zero (never) to three (very high). The score of each article is converted into t scores with the average of 50 and standard deviation of ten (i.e. $50 \pm 10$ ). If the $t$ scores are 2 standard deviations higher than the average, the individual has a problem (24). Abdekhodaie et al. (25) reported the sensitivity and specificity of respectively $90.3 \%$ and $81.2 \%$ for CPRS-48 in diagnosing children with ADHD.

After CPRS-48 was completed by the parents and the children were identified with any form of ADHD, the children were referred to an expert psychiatrist, as the project administrator, to confirm ADHD diagnosis by clinical interview and based on DSM-IV $(8-10,14)$. It should be mentioned that ADHD diagnosis for children with this disorder was confirmed by evaluating its differential diagnoses such as hyperthyroidism (by measuring thyroidstimulating hormone and free thyroxin) and lead poisoning (blood lead level $>10 \mu \mathrm{g} / \mathrm{dL}$ or $>0.48 \mu \mathrm{mol} / \mathrm{L}$ ) (26).

The collected data were analyzed with SPSS 18 (SPSS Inc, Chicago, Illinois, the United States) and descriptive statistics methods for frequency determination. Independent-samples $t$ test and Chi square test were used for data analysis. P values $<0.5$ were considered statistically significant. This study was confirmed by Ethics Committee of Arak University of Medical Sciences and all stages of 
this study conformed to Helsinki declaration principles and a written informed consent was obtained from all of the participants' parents.

\section{Results}

During six month of study, 132 children undergoing CAPD were analyzed against the inclusion and exclusion criteria and 32 (24.2\%) were excluded and were replaced with other qualified participants. In order to find replacements, 36 patients undergoing CAPD were analyzed based on the inclusion and exclusion criteria. Among 32 excluded patients, 24 (75\%), 6 (18.7\%), and 2 (6.2\%) patients were excluded respectively due to parental dissatisfaction to complete of CPRS-48 questionnaire, history of intellectual disabilities, and history of considerable psychiatric disorders; One child with history of ADHD be- fore developing CKD and another with history of obsessive- compulsive disorder. For control group, 100 out of 108 investigated children were selected. The remainder had been studied, due to the lack of cooperation of their parents in completing the questionnaires.

The mean and standard deviation values of background characteristics of children CAPD and control groups were as follows: age, $7.9 \pm 2.09$ and $8.2 \pm 1.23$ year, respectively $(\mathrm{P}=0.21$ ); birth weight, $2769.9 \pm 636.6$ and $3100.1 \pm 641 \mathrm{~g}$, respectively ( $\mathrm{P}=0.001)$; and mother's age at birth, $25.37 \pm$ 5.71 and $25.02 \pm 5.55$ year, respectively $(P=0.66)$. The mean age of children with ADHD inattentive type and ADHD hyperactive-impulsive type were $8.8 \pm 1.81$ and $8.37 \pm 1.59$ years, respectively $(\mathrm{P}>0.05)$. Other demographic, clinical, and prenatal data of the case and control groups as well as children with ADHD inattentive type and hyperactive-impulsive type are listed in Tables 1 and 2.

Table 1. Clinical and Demographic Characteristics in in the Dialysis and Control Groups a,b

\begin{tabular}{|c|c|c|c|}
\hline Variables & CAPD Group & Control Group & PValue $^{\mathrm{C}}$ \\
\hline Sex & & & $>0.05$ \\
\hline Female & 51 & 50 & \\
\hline Male & 49 & 50 & \\
\hline Gestational age & & & 0.001 \\
\hline Full term & 67 & 88 & \\
\hline Premature (<37 wk) & 29 & 9 & \\
\hline Post-term (> $40 \mathrm{wk})$ & 4 & 3 & \\
\hline Maternal education & & & 0.001 \\
\hline College & 45 & 23 & \\
\hline High school & 52 & 57 & \\
\hline Elementary school & & 20 & \\
\hline Household incomes & 3 & & 0.001 \\
\hline Low ${ }^{\mathrm{d}}$ & 64 & 44 & \\
\hline Moderate $^{\mathrm{e}}$ & 35 & 33 & \\
\hline $\operatorname{High}^{\mathrm{f}}$ & 1 & 23 & \\
\hline Marital status & & & 0.467 \\
\hline Intact marriage & $84(84)$ & $79(79)$ & \\
\hline Divorced & 16 & 21 & \\
\hline Patient with siblings & & & $>0.05$ \\
\hline Yes & 3 & 2 & \\
\hline No & 97 & 98 & \\
\hline Type of delivery & & & 0.001 \\
\hline Vaginal delivery & 71 & 91 & \\
\hline Cesarean delivery & 29 & 9 & \\
\hline ADHD types ${ }^{g}$ & & & 0.001 \\
\hline Yes & 43 & 12 & \\
\hline No & 57 & 88 & \\
\hline Newborn jaundice & & & $>0.05$ \\
\hline Yes & 4 & 3 & \\
\hline No & 96 & 97 & \\
\hline \multicolumn{4}{|c|}{$\begin{array}{l}\text { a Abbreviations: CAPD, continuous ambulatory peritoneal dialysis; and ADHD, attention-deficit/hyperactivity disorder. } \\
\text { b Data are presented as No. (\%), } \mathrm{n}=100 \text {. } \\
\text { c P values }<0.5 \text { were considered statistically significant. } \\
\text { d Family monthly income }<5 \text { million Rials. } \\
\text { e Family monthly income of } 5 \text { million to } 10 \text { million Rials. } \\
\text { f Family monthly income }>10 \text { million Rials. } \\
\text { g Total subjects with any type of the inattentive type, hyperactive-impulsive type, and type of ADHD. }\end{array}$} \\
\hline
\end{tabular}


Table 2. Clinical and Demographic Characteristics in Children With Inattentive and Hyperactive-Impulsive Types of Attention-Deficit/Hyperactivity Disorder a,b

\begin{tabular}{|c|c|c|c|}
\hline Variables & ADHD Inattentive Type $(\mathbf{n}=\mathbf{2 1})$ & ADHD Hyperactive-Impulsive Type ( $n=34)$ & P Value ${ }^{c}$ \\
\hline Sex & & & 0.1 \\
\hline Female & $6(28.57)$ & $18(52.94)$ & \\
\hline Male & $15(71.42)$ & $16(47.05)$ & \\
\hline Gestational age & & & 0.001 \\
\hline Full term & $6(28.57)$ & $13(38.23)$ & \\
\hline Premature (<37 wk) & $13(61.9)$ & $21(61.76)$ & \\
\hline Post-term (> $40 \mathrm{wk})$ & $2(9.52)$ & 0 & \\
\hline Maternal education & & & 0.376 \\
\hline College & $10(47.61)$ & $11(32.35)$ & \\
\hline High school & $10(47.61)$ & $21(61.76)$ & \\
\hline Elementary school & $1(4.76)$ & $2(5.88)$ & \\
\hline Household incomes & & & 0.003 \\
\hline Low ${ }^{d}$ & $7(33.33)$ & $26(76.47)$ & \\
\hline Moderate $\mathrm{e}^{\mathrm{a}}$ & $13(61.9)$ & $7(20.58)$ & \\
\hline $\operatorname{High}^{\mathrm{f}}$ & $1(4.7)$ & $1(2.9)$ & \\
\hline \multicolumn{4}{|l|}{ Marital status } \\
\hline Intact marriage & $6(28.57)$ & $34(100)$ & \\
\hline Divorced & $15(71.42)$ & 0 & \\
\hline Patient with siblings & & & 0.001 \\
\hline Yes & $4(19.04)$ & 0 & \\
\hline No & $17(80.9)$ & $34(100)$ & \\
\hline Type of delivery & & & 0.001 \\
\hline Vaginal delivery & $8(30.09)$ & $13(38.23)$ & \\
\hline Cesarean delivery & $13(61.9)$ & $21(61.76)$ & \\
\hline Newborn jaundice & & & 0.936 \\
\hline Yes & $1(4.76)$ & $1(2.94)$ & \\
\hline No & $20(95.23)$ & $33(97.05)$ & \\
\hline
\end{tabular}

a ADHD; Attention-deficit/hyperactivity disorder.

$\mathrm{b}$ Data are presented as No. (\%), $\mathrm{n}=21$ for ADHD Inattentive Type and $\mathrm{n}=34$ for ADHD Hyperactive-Impulsive Type.

c $P$ Values $<0.5$ were considered statistically significant.

$\mathrm{d}$ Family monthly income $<5$ million Rials.

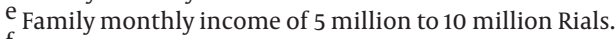

$\mathrm{f}_{\text {Family monthly income }>10 \text { million Rials. }}$

Table 3. Frequency of children with any type of Attention-Deficit/Hyperactivity Disorder in the study groups ${ }^{\text {a }}$

\begin{tabular}{lccc}
\hline ADHD $^{\mathrm{b}}$ Type & Case $^{\mathrm{c}}$ & Control $^{\mathrm{d}}$ & P Value $^{\mathrm{C}}$ \\
\hline Inattentive type & $16(16)$ & $5(5)$ & 0.01 \\
Hyperactive-impulsive type & $27(27)$ & $7(7)$ & 0.002 \\
Combined type & 0 & 0 & - \\
\hline
\end{tabular}

a Data are presented as No.(\%).

b Attention-deficit/hyperactivity disorder.

c Children undergoing chronic ambulatory peritoneal dialysis.

d Healthy children.

Of the 200 children (100\%) in both groups, 145 children (72.5\%) had not any type of ADHD and out of 55 patients (27.5\%), 21 (10.5\%) and 34 (17\%) had ADHD inattentive type and ADHD hyperactive-impulsive type, respectively. none of the children had ADHD combined type. The prevalence of ADHD inattentive type and ADHD hyperactive-impul- 
sive type was significantly higher in children undergoing CAPD than was in the healthy children $(\mathrm{P}=0.01$ and $\mathrm{P}=$ 0.002 , respectively) (Table 3 ).

There was no significant difference between the mean duration of dialysis between 145 children without ADHD (195.31 \pm 196.65 days) and children with ADHD (196.65 \pm 7.44) $(\mathrm{P}=0.238)$. Moreover, the means of CAPD duration in children with ADHD inattentive type and ADHD hyperactive-impulsive type were $197.67 \pm 13.22$ and $194.5 \pm 10.74$ days, respectively $(\mathrm{P}=0.63)$.

\section{Discussion}

Based on our study, inattentive and hyperactive-impulsive types of ADHD are more prevalent in children with ESRD undergoing CAPD. Yet, no study has been conducted on the association between ADHD and PD in children. However, different studies have been conducted on psychiatric disorders in children with various stage of CKD. Bakr et al. (3) studied 19 children with CKD who did not need dialysis and 19 other with ESRD for psychiatric disorders. According to evidence, it was indicated that $18.4 \%$, $10.3 \%, 7.7 \%, 5.1 \%$, and $2.6 \%$ of the subjects had adjustment disorder, depression, cognitive disorder, anxiety, and elimination disorder. The prevalence of the above disorder was calculated at $68.4 \%$ and $36.8 \%$ in dialysis and nondialysis groups, respectively. In another study on 30 children with CKD and CPD, 30 children who had undergone renal implantation and 33 healthy children, Fukunishi and Honda (4) indicated a significant difference in the prevalence of adjustment disorder between the children in three groups; dialysis and control groups had the highest and lowest prevalence of this disorder, respectively. Slickers et al. (5) indicated a significant association between decline in cognitive functions and the severity of CKD in children with different stage of CKD. In a study on children with ESRD and healthy children, Fukunishi and Kudo (7) indicated that the prevalence of anxiety and depression was significantly higher in children with ESRD and PD than in healthy children.

According to the earlier studies, ADHD is more prevalent in male than in female children $(14,27,28)$. However, based on our results, the incidence rates of ADHD inattentive type and ADHD hyperactive-impulsive type were significantly higher in boys and in girls, respectively. We also investigated the correlation between the duration of PD and ADHD and could not detect any significant correlation between them. Unfortunately, the evidences on the association between psychiatric disorders such as, ADHD, and duration of PD are few. Therefore, evaluating the association between duration of dialysis and various psychiatric disorders (based on the type and severity of them) seems essential.

As a conclusion, based on the previous studies, psychological disorders are more frequent in children with CKD and children with ESRD on CAPD, compared to healthy children or children with early-stages of CKD. In our in- vestigation, we showed that inattentive and hyperactiveimpulsive types of ADHD were significantly more prevalent in children with CAPD than in healthy children. Therefore, psychiatric interventions seem to be useful to diagnose ADHD in children with ESRD undergoing CAPD. However, following items make conducting further investigations on ADHD in children with different stages of CKD essential:

1) ADHD is a common debilitating disorder of childhood. Therefore, investigation of the associated conditions in children is essential.

2) In contrast to other psychologic disorders, evidence of the frequency of ADHD in children with different stages of CKD is limited.

3) Although correlation between CKD and some psychologic disorders as well as clinical effect of ADHD on some impairments associated with the disease have already been investigated, mutual effect of ADHD and different types of CKD on clinical course and the response to treatment for both types of disorder are unclear.

Among the limitations of our study, we may indicate lack of cooperation of some parents to fill in ADHD questionnaire and the psychiatric examination of the child performed by the psychiatrist. Although this criterion led to excluding some eligible children, we attempted to remove such limitation by encouraging the parents for possible usefulness of the study and help them fill in the questionnaire. In addition, lack of investigating the correlation between some clinical factors, such as the association between the quality of dialysis and ADHD, was another limitation of our study. Therefore, future studies with consideration of more demographic, epidemiologic, and clinical factors are recommended.

Based on current study, ADHD is more prevalent in patient with ESRD undergoing CAPD. Therefore, screening methods for ADHD is necessary in these patients. However, with regard to the lack of evidence in this field, further studies are recommended.

\section{Acknowledgements}

The research team wishes to thank vice chancellor of research for their financial support and children and their parents who participated in this research.

\section{Financial Disclosure}

This study was financially supported by Arak University of Medical Sciences, Arak, Iran.

\section{References}

1. Gerson AC, Butler R, Moxey-Mims M, Wentz A, Shinnar S, Lande $\mathrm{MB}$, et al. Neurocognitive outcomes in children with chronic kidney disease: Current findings and contemporary endeavors. Ment Retard Dev Disabil Res Rev. 2006;12(3):208-15.

2. Neu AM, Ho PL, McDonald RA, Warady BA. Chronic dialysis in children and adolescents. The 2001 NAPRTCS Annual Report. Pediatr Nephrol. 2002;17(8):656-63.

3. Bakr A, Amr M, Sarhan A, Hammad A, Ragab M, El-Refaey A, et al. 
Psychiatric disorders in children with chronic renal failure. Pediatr Nephrol. 2007;22(1):128-31.

4. Fukunishi I, Honda M. School adjustment of children with endstage renal disease. Pediatr Nephrol. 1995;9(5):553-7.

5. Slickers J, Duquette P, Hooper S, Gipson D. Clinical predictors of neurocognitive deficits in children with chronic kidney disease. Pediatr Nephrol. 2007;22(4):565-72.

6. McQuillan R, Jassal SV. Neuropsychiatric complications of chronic kidney disease. Nat Rev Nephrol. 2010;6(8):471-9.

7. Fukunishi I, Kudo H. Psychiatric problems of pediatric end-stage renal failure. Gen Hosp Psychiatry. 1995;17(1):32-6.

8. Willcutt EG, Nigg JT, Pennington BF, Solanto MV, Rohde LA, Tannock R, et al. Validity of DSM-IV attention deficit/hyperactivity disorder symptom dimensions and subtypes. J Abnorm Psychol. 2012;121(4):991-1010.

9. Yousefi P, Salehi B, Firouzifar M, Sheikholeslami H. The Correlation between Attention Deficit Hyperactivity Disorder and Enuresis in Children with Nocturnal Enuresis. J Isfahan Med School. 2012;30:1-8.

10. Pineda DA, Lopera F, Palacio JD, Ramirez D, Henao GC. Prevalence estimations of attention-deficit/hyperactivity disorder: differential diagnoses and comorbidities in a Colombian sample. Int J Neurosci. 2003;113(1):49-71.

11. Thome-Souza S, Kuczynski E, Assumpcao FJ, Rzezak P, Fuentes D, Fiore L, et al. Which factors may play a pivotal role on determining the type of psychiatric disorder in children and adolescents with epilepsy? Epilepsy Behav. 2004;5(6):988-94.

12. Chou IC, Chang YT, Chin ZN, Muo CH, Sung FC, Kuo HT, et al. Correlation between epilepsy and attention deficit hyperactivity disorder: a population-based cohort study. PLoS One. 2013;8(3).

13. Chronis-Tuscano A, Molina BS, Pelham WE, Applegate B, Dahlke A Overmyer M, et al. Very early predictors of adolescent depression and suicide attempts in children with attention-deficit/hyperactivity disorder. Arch Gen Psychiatry. 2010;67(10):1044-51.

14. Yang Y, Jalal FY, Thompson JF, Walker EJ, Candelario-Jalil E, Li L, et al. Tissue inhibitor of metalloproteinases-3 mediates the death of immature oligodendrocytes via TNF-alpha/TACE in focal cerebral ischemia in mice. J Neuroinflammation. 2011;8:108.

15. Rowland AS, Lesesne CA, Abramowitz AJ. The epidemiology of attention-deficit/hyperactivity disorder (ADHD): a public health view. Ment Retard Dev Disabil Res Rev. 2002;8(3):162-70.

16. Richer LP, Shevell MI, Rosenblatt BR. Epileptiform abnormalities in children with attention-deficit-hyperactivity disorder. Pediatr
Neurol. 2002;26(2):125-9.

17. Hammerness P, Monuteaux MC, Faraone SV, Gallo L, Murphy H, Biederman J. Reexamining the familial association between asthma and ADHD in girls. JAtten Disord. 2005;8(3):136-43.

18. Burgu B, Aydogdu O, Gurkan K, Uslu R, Soygur T. Lower urinary tract conditions in children with attention deficit hyperactivity disorder: correlation of symptoms based on validated scoring systems. J Urol. 2011;185(2):663-8.

19. Okur M, Ruzgar H, Erbey F, Kaya A. The evaluation of children with monosymptomatic nocturnal enuresis for attention deficit and hyperactivity disorder. Int J Psychiatry Clin Pract. 2012;16(3):229-32.

20. Eedharam RJ, Avner ED. End stage renal disease. Kliegman RM, Stanton BF, Geme JW, Schor NF, Behrman RE editors. Philadelphia: WB Saunders; 2011.

21. Beladi-Mousavi SS, Alemzadeh-Ansari MJ, Alemzadeh-Ansari MH, Beladi-Mousavi M. Long-term survival of patients with end-stage renal disease on maintenance hemodialysis: a multicenter study in Iran. Iran J Kidney Dis. 2012;6(6):452-6.

22. Mahan JD, Patel HP. Recent advances in pediatric dialysis: a review of selected articles. Pediatr Nephrol. 2008;23(10):1737-47.

23. Stromme P, Diseth TH. Prevalence of psychiatric diagnoses in children with mental retardation: data from a population-based study. Dev Med Child Neurol. 2000;42(4):266-70.

24. Hale JB, How SK, Dewitt MB, Coury DL. Discriminant validity of the Conners' scales for ADHD subtypes. Current Psychology. 2001;20(3):231-49.

25. Abdekhodaie Z, Tabatabaei SM, Gholizadeh M. The investigation of ADHD prevalence in kindergarten children in northeast Iran and a determination of the criterion validity of Conners' questionnaire via clinical interview. Res Dev Disabil. 2012;33(2):357-61.

26. Nishioka T, Yasuda M, Takeshima T, Haga H, Miyai Y, Shibata K, et al. Radiation-induced cancer cell repopulation: a possible mechanism implied by experiments using transplantable mouse-derived sarcoma cell line. Cell Struct Funct. 2011;36(1):13-20.

27. Arman AR, Ersu R, Save D, Karadag B, Karaman G, Karabekiroglu $\mathrm{K}$, et al. Symptoms of inattention and hyperactivity in children with habitual snoring: evidence from a community-based study in Istanbul. Child Care Health Dev. 2005;31(6):707-17.

28. Yoshimasu K, Yamashita H, Kiyohara C, Miyashita K. [Epidemiology, treatment and prevention of attention deficit/hyperactivity disorder: a review]. Nihon Koshu Eisei Zasshi. 2006;53(6):398-410. 